\title{
Eine neue Art der Gattung Melanochelia Rond.
}

Von V. v. Röder in Hoym (Herzogth. Anhalt).

(Ein dipterologischer Beitrag.)

Die Gattung Melanochelia Rnd. gehört zu jener Anthomyiden-Gruppe, bei welcher die Augen in beiden Geschlechtern weit getrennt sind. Herr Meade hat diese Gruppe in $2 \mathrm{Ab}$ theilungen geordnet. $\mathrm{Zu}$ der ersten gehören diejenigen Gattungen, bei welchen die Flügelschüppchen ungleich sind: das obere bedeckt das untere nicht. Die zweite Abtheilung. enthält Gattungen mit gleichen, sich deckenden Flügelschüppchen. Die Gattung Melanochelia Rnd. gehört zur ersten Gruppe und zeichnet sich dadurch aus, dass die Stirn und das Untergesicht hervorragend sind. Bis jetzt war nur eine deutsche Art in dieser Gattung vertreten. Ich sammelte eine neue Art vor mehreren Jahren am Meeresstrande der Insel Norderney (im Juli). Sie unterscheidet sich von Mel. riparia Fall:

Fronte modice prominente, abdomine maculis distincte discretis

Fronte valde prominente, abdomine sine maculis distinctis. Melan. maritima n. ep.

\section{Melanochelia maritima n. spec.}

6 Tota cana. Cap.te albo-micante; oculis remotis, fionte albo-micante in medio linea tenuissima nigra in extremitate excavata; epistomate valde prominente; antennis nigris, brevibus; seta nuda; palpis nigris, filiformibus, longis. Thorace griseo-cano; angulo humerali albo-micante; in medio thoracis strigis obscuris tenuissimis. Scutello griseo-cano. Abdomine ovato cano-unicolore, in aliqua conversione in medio lucida linea longitudinali. Appendicibus analibus retractis vel vix porrectis. Fronte abdomineque brevibus, tenuibus setis in punctis nigris tenuissimis dispositis. Pedibus nigris, cinereo-pollinosis. Alis basi venarum flavis, ceterum hyalinis. Nervo transverso exteriore, nervo transverso medio modice approximato, recto; squamis inaequalibus albis. Long.: circa $6 \mathrm{~mm}$. Habitat in insula Norderney in litore maris.

Weissgrau. Stirn weissgrau schimmernd, in der Mitte mit einer sehr schmalen schwarzen Mittelstrieme, die hinten ausgerandet ist (d. h. in 2 schmale Enden verläuft); auf beiden Seiten dieser Längsstrieme befinden sich feine Börstchen, die auf sehr feinen schwarzen Pünktchen stehen. Augen sehr weit von einander entfernt; Stirn sehr vorstehend, so dass. 
das Untergesicht sehr hervortritt. Untergesicht weissschimmernd. Fühler kurz, schwarz; die beiden ersten Glieder fast gleich lang, zusammen so lang als das dritte; Fühlerborste nackt; der Mundrand mit feinen Börstchen besetzt; Taster schwarz, fadenförmig, gegen das Ende ein wenig verdickt. Thorax weissgrau, in der Mitte mit sehr feinen dunkleren Striemen und mit stärkeren und schwächeren Borsten besetzt. Die Schulterecken bis geǵen die Brustseiten weissschimmernd. Schildchen grauweiss mit 4 schwarzen Borsten. Hinterleib grauweiss, in gewisser Richtung mit einer helleren Längsstrieme auf der Mitte und mit feinen Borsten, welche auf schwarzen Punkten stehen; die Analanhänge sind eingezogen oder wenigstens kaum vorstehend, nur der letzte Bauchring läuft in eine kleine vorstehende Spitze aus. Beine schwarz, graulich bestäubt. Flügel an der Basis gelblich; sonst glas. hell; die hintere Querader der kleinen Querader mässig nahestehend. Schüppchen: das untere das obere weit überragend.

\section{Asyndulum montanum n. spec.}

Von V. v. Röder in Hoym (Herzogth. Anhalt).

(Ein dipterologischer Beitrag.)

Maxima species generis Asynduli of ${ }^{\circ}$. Epistomate flavo; rostro brevi nigro; antennis nigro-fuscis; thorace nigro, aut lateribus thoracis et angulo humerali flavis, aut tribus vittis nigris longitudinalibus; abdomine nigro, segmento quarto et sequentibus totis flavis; coxis pedibusque flavis; alis subhyalinis, adversus apicem et adversus marginem posticum paulo saturatius fusco-cinereis. Long. $8-8^{1 / 2} \mathrm{~mm}$.

Nigrum; epistomate flavo; antennis nigro-fuscis; rostro brevi nigro; thorace aut nigro, lateribus thoracis et angulo humerali flavis $\hat{\sigma}$, aut flavo et tribus vittis nigris longitudinalibus ornato $f$ et ( $\delta$ var.) Scutello piceo aut flavo.

Segmentis tribus primis abdominis nigris, sequentibus ultimis flavis; alis subhyalinis, colore fusco-cinereo leviter tinctis adversus apicem, in cellula cubitali saturatius fuscotinctis et adversus dimidium apicale marginis postici paulo saturatius fusco-cinereis; venis alarum nigro-fuscis, similiter atque in Asyndulo femorali $\mathrm{Mg}$.

Habitat White Mountains. (America borealis.) 


\section{$2 \mathrm{BHL}$ Biodiversity Heritage Library}

Röder, Victor von. 1887. "Eine neue Art der Gattung Melanochelia ROND." Wiener entomologische Zeitung 6, 115-116.

https://doi.org/10.5962/bhl.part.17741.

View This Item Online: https://www.biodiversitylibrary.org/item/44060

DOI: https://doi.org/10.5962/bhl.part.17741

Permalink: https://www.biodiversitylibrary.org/partpdf/17741

\section{Holding Institution}

Smithsonian Libraries

\section{Sponsored by}

Smithsonian

\section{Copyright \& Reuse}

Copyright Status: NOT_IN_COPYRIGHT

This document was created from content at the Biodiversity Heritage Library, the world's largest open access digital library for biodiversity literature and archives. Visit BHL at https://www.biodiversitylibrary.org. 